\title{
EXTERNAL WEB SERVICES FOR CONSTRUCTION SECTOR SMES
}

\author{
Rimantas Gatautis \\ Kaunas University of Technology \\ Laisvès av. 55, LT 44309 Kaunas, Lithuania \\ rgataut@ktu.lt
}

\author{
Elena Vitkauskaite \\ Kaunas University of Technology \\ Laisvès av. 55, LT 44309 Kaunas, Lithuania \\ elevitk@ktu.lt
}

\begin{abstract}
Nowdays construction sector SMEs lack of e-business solutions. Paper reflects finding of e-NVISION project evaluating SMEs need for external services and providing decription of proposed Company/Supplier Information Retrieval Service, Supplier/Company Discovery Service, Tender Configurator, Procurement Configurator, Service for the Location of Services, Service Registry, Connector to EU Public Tender Service web services which will be utilized by construction sector SMEs through different types of intermiadiaries.
\end{abstract}

\section{KEYWORDS}

Construction sector, SMEs, External web services

\section{INTRODUCTION}

Electronic business activity is less developed in the construction industry than in manufacturing sectors. There are a multitude of standards, technical specifications, labels, and certification marks. Electronic business activity in construction is very limited compared to the other sectors studied by e-Business W@tch. Many companies prefer to be re-active rather than pro-active in their use of ICT. The construction industry has yet to show the same level of ICT driven improvement of productivity as in other industries. This can partly be explained by the nature of the work and the type of production involved in construction processes. It is also related to slow uptake of ICT in a sector which is dominated by SMEs. Large enterprises in the industry and new sector entrants have adopted ICT based production methods. However, there is still great potential for further ICT uptake, for example: production planning systems, ERP-systems with financial components, inventory management systems, supply chain management (SCM) and mobile solutions. Business process integration may be a key driver for ICT adoption in the future. Most companies in the sector tend to organise work around individual construction projects which has led to a fragmentation in ICT use and e-business activity, characterised by a lack of commonly accepted standards, technical specifications and labels $[1,2,3]$.

The paper presents findings from the EU funded $6^{\text {th }}$ Framework project e-NVISION. project aims to develop and validate an innovative e-Business platform for the SMEs allowing them: to model and adapt in their organizations particular business sce- 
narios requested by their customers and suppliers; to integrate all their enterprise applications following a service-oriented architecture; and to incorporate legal, economical and social services offered by external organizations, with the overall goal of facilitating the participation of SMEs, especially those coming from the New Member States, in European e-Business scenarios. e-NVISION e-Business Model is based on three pillars: business messages, internal business processes and semantic services. These pillars are interconnected through a set of Construction Ontologies as shown in the 1 figure.

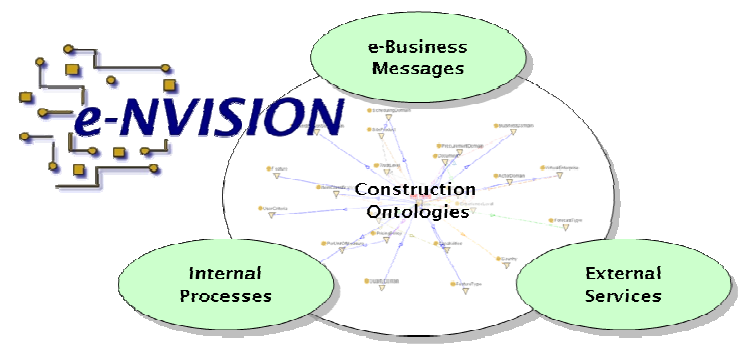

Figure 1. e-NVISION e-busisness model for construction sector SMEs

- Business messages, which are sent between the different actors that take part in a construction project, in order to:

- Invite partners to participate in a tender,

- Involve suppliers and subcontractors in the construction project,

- Notify design changes, and

- Notify site incidents.

- Internal business processes, which define the tasks to be done internally in a construction company when an e-NVISION message is received and the way the business processes are integrated with the back-end systems of the company, and

- External services, which provide the information needed to govern the flow of the business processes. The construction company, especially if it is an SME, does not have enough resources to maintain this information internally.

- Construction Ontology, which defines the common concepts, entities and relationships.
SME implementing business processes has to consult information previously processed and stored by the own SME, integration services, or by external organisations, external services. It is necessary to dedicate a lot of time and human resources to obtain this kind of information, from previous experiences or from external sources of information, to process it and to register it in the back-office systems [4].

However, SMEs do not have these resources, and sometimes they are not able to participate in some business activities due to this fact. e-NVISION proposes to externalise these services to other organisations like Chambers of Commerce, Construction Associations or Clusters, Consultancy Firms, or Local Governments. They have the resources that SMEs do not have and can provide this information at a lower prize. The result is that SMEs can obtain similar information to that managed by large companies.

External Services will be offered by external organisations to the Construction SMEs. Depending on the type of organisation, Construction Association, Cluster, Public Administration, Chamber of Commerce, Consultancy Firm, etc., the Business Model could differ [5], [6].

According to the functionality provided by the external services, they can be grouped by the following categories:

- Search and configuration services.

- Company information retrieval services. They provide additional information about a company. This information is useful when the SME has to decide whether to work or not with that company in a construction project.

- Other information retrieval services.

- Interoperability services.

\section{INTEREST BY THE CONSTRUCTION SMES}

In order to validate the e-Business scenarios and requirements defined in the e-NVISION project the empirical survey was carried out. The objective of this survey was to validate the assumptions that had been made and the results that had been obtained with external user groups and industry actors from the Construction Sector, 
The following chart shows the results of 29 interviews and mail contacts with construction companies from France, Lithuania, Poland, Spain and Slovenia.

The company distribution by country was the following (fig. 2):

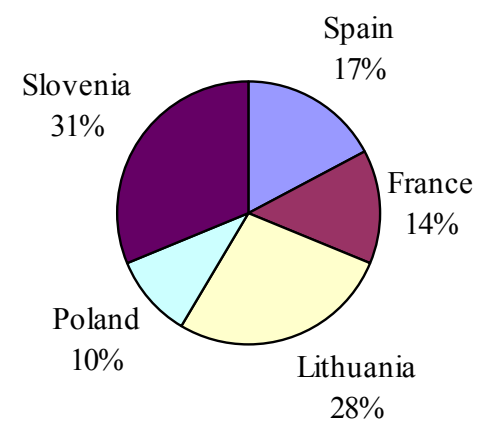

Figure 2. Company distribution by country

\section{SELECTION OF E-NVISION SERVICES}

As it was stated before one of the main problems that e-NVISION tries to solve is the configuration of a construction project team. To do so, the implementation of the search and configuration services is crucial. In fact, e-Tendering and e-Procurement eNVISION scenarios could not take place without them.

Furthermore, SMEs consulted in the Validation of the e-NVISION scenarios have expressed great interest for these services as shown in the table 1 .

Table 1. Interest for external services

\begin{tabular}{|l|l|c|}
\hline Category & \multicolumn{1}{|c|}{ External Service } & $\begin{array}{c}\text { SMEs } \\
\text { Interest }\end{array}$ \\
\hline $\begin{array}{l}\text { Search and } \\
\text { configura- } \\
\text { tion }\end{array}$ & $\begin{array}{l}\text { Company/Supplier Infor- } \\
\text { mation Retrieval Service }\end{array}$ & $61,90 \%$ \\
\cline { 2 - 3 } & $\begin{array}{l}\text { Supplier/Company Discov- } \\
\text { ery Service }\end{array}$ & $61,90 \%$ \\
\cline { 2 - 3 } & Tender Configurator & $38,1 \%$ \\
\cline { 2 - 3 } & Procurement Configurator & $28,57 \%$ \\
\cline { 2 - 3 } & $\begin{array}{l}\text { Service for the Location of } \\
\text { Services }\end{array}$ & $28,57 \%$ \\
\cline { 2 - 3 } & Service Registry & $28,57 \%$ \\
\hline $\begin{array}{l}\text { Information } \\
\text { retrieval }\end{array}$ & $\begin{array}{l}\text { Connector to EU Public } \\
\text { Tender Service. }\end{array}$ & $47,62 \%$ \\
\hline
\end{tabular}

\begin{tabular}{|l|l|c|}
\hline Category & \multicolumn{1}{|c|}{ External Service } & $\begin{array}{c}\text { SMEs } \\
\text { Interest }\end{array}$ \\
\hline \multirow{5}{*}{$\begin{array}{l}\text { Company } \\
\text { information } \\
\text { retrieval }\end{array}$} & $\begin{array}{l}\text { Technical regulation and } \\
\text { standards retriever. }\end{array}$ & $42,86 \%$ \\
\cline { 2 - 3 } & $\begin{array}{l}\text { Trust Agents } \\
\text { Agents for the Prequalifica- } \\
\text { tion of SMEs }\end{array}$ & $33,33 \%$ \\
\cline { 2 - 3 } & $\begin{array}{l}\text { Previous Technological } \\
\text { References Service }\end{array}$ & $28,57 \%$ \\
\cline { 2 - 3 } & $\begin{array}{l}\text { Customers Satisfaction Ser- } \\
\text { vice }\end{array}$ & $9,52 \%$ \\
\cline { 2 - 3 } & Legal Agents & $4,76 \%$ \\
\hline \multirow{2}{*}{$\begin{array}{l}\text { Inter- } \\
\text { operability }\end{array}$} & $\begin{array}{l}\text { Automatic translation ser- } \\
\text { vices/tools. }\end{array}$ & $33,33 \%$ \\
\cline { 2 - 3 } & Classificator & $14,29 \%$ \\
\cline { 2 - 3 } & $\begin{array}{l}\text { Standardised Voluntary } \\
\text { Quality Marks and Certifica- } \\
\text { tions. }\end{array}$ & $9,52 \%$ \\
\hline Insurance & Insurance Company & $9,52 \%$ \\
\hline
\end{tabular}

\section{EXTERNAL SERVICES FOR SMES}

\subsection{Tender Configurator}

The Tender Configurator is in charge of analysing a tender and according to the tender model, decomposing the tender in sub-tenders or sub-works that can be carried out by and matched to different profiles of SMEs, i.e. if we consider a tender to build a house we can divide it in a sub-tender for masonry, a sub-tender for electricity and so on. This way, the Tender Configurator will offer several possible Virtual Enterprises or groups of SMEs with the skills and competences to participate in the tender and to carry out the tender works.

This service is a core service as it provides one of the main functionalities considered in the eTendering scenario, i.e. it returns different alternatives of groups of SMEs with the skills and competences to carry out certain tender works.

\subsection{Service for the Location of Services}

The external Service for the Location of Services provides the means to search for Semantic Web Services (registered in the UDDI repository) based on the capability descriptions, i.e. inputs and outputs of a service. This way, an e-NVISION company will be able to find a service not only using keyword search but using functionality or capability search. 
In this service, core of all discovery mechanisms is a Matching Engine that takes the requester description of an ideal Web Service to interact with advertisements of providers. The Matching Engine finds Web Service(s) that more closely fit the description and the result is a flexible matching which shows the relation between advertisement and request.

This service is considered as core external service as it provides one of the main functionalities offered by semantic services, i.e. automatic search mechanism based on capability descriptions and not only on keywords.

\subsection{Company / Supplier Information Retrieval Service}

Since not all companies will be members of eNVISION, this service covers two aspects:

- collecting and updating information from the SMEs that are already registered in the eNVISION platform.

- capturing information from newly registered SMEs - new members of the e-NVISION platform.

This service maps the information of the companies/suppliers in order to formalize this information in terms of the company model defined in the eNVISION ontology.

This service is considered as added value service because the information of the companies/suppliers can be collected and entered into e-NVISION using web forms. However, the e-NVISION consortium considers that it would be very useful for SMEs to be able to provide the information about their enterprises and update it automatically instead of manually.

\subsection{Supplier / Company Discovery Service}

The Supplier/Company Discovery Service gives the possibility of searching for suppliers that offer a certain item identified by a standard classification system. An item is any product, material, service, machinery or equipment. Given a certain item as input the Web service offers an unordered list of companies that can provide it.

Besides, this service can also provide detailed information about a company, i.e. it allows searching for a company given some kind of information such as its name, or its VAT number, or its organisation identifier. In this case, the service returns all the information related to the company: registered and trading name, address, contact information, etc.

On the one hand, it is necessary in the e-Tendering scenario to have a service that searches for companies that can perform certain construction works. On the other hand, it is necessary in the e-Procurement scenario to have a service that searches for companies that can supply materials, products, machinery or equipment. For these reasons, the Supplier/Company Discovery Service is considered as a core external service.

\subsection{Procurement Configurator}

The Procurement Configurator service provides means to configure the list of potential suppliers that can provide a certain schedule of deliveries required by an investor. This schedule of deliveries consists of a list of products, materials, machinery and equipment identified by a standard classification system. This service takes the list of items needed from the schedule of deliveries and matches them with those offered by the companies. The configurator will provide different possible configurations of companies that can provide the schedule of deliveries ranked according to the criteria defined by the user [7].

This service is a core service as it provides one of the main functionalities considered in the eProcurement scenario, i.e. it returns different alternatives of configurations of SMEs that can provide a certain schedule of deliveries.

\subsection{Connector to EU Public Tender Service}

This service checks different national and European means (portals, papers) where the invitations to tenders are published.

It can also offer the possibility to publish (private) tenders directly. There are many similar services on the web (see information about www.ekapija.com bellow). Such services normally require "human" component because it's almost impossible to compare different types of call for tenders in different countries automatically (electronically). The chal- 
lenge for this service is to enable electronically retrieval of key information about individual tender. It must also tackle the problem of different languages, the problems of different structure of individual calls for tender, etc [8].

In the e-Tendering scenario it is necessary to have a tool to publish tenders in terms of the ontology defined in the project. For this reason, the e-NVISION project will provide an application with a graphical user interface that allows the user to enter the information about the tender and this information will be automatically mapped in terms of the ontology.

From the technical point of view, the connector to EU Public Tender service is considered as an added value service as it provides a mechanism to automatically retrieve information about tenders published in the TED portal.

However, in the external validation survey, SMEs have declared the importance for them to have a mechanism that automatically retrieves the information about tenders published in the TED portal so that they can keep constantly informed about new tenders. Although automatic processing of text is a very complex issue which is still under research, the e-NVISION project will provide a service that automatically retrieves as much information as possible about the tender.

\section{CONCLUSIONS}

It is a fact that the future business scenario will be global, open, collaborative, dynamic, adaptive, frictionless and consistent. The question is whether the SMEs are ready to participate in it or not. Therefore, more than as an opportunity, SMEs have to see it as a necessity, as a way of survival. Public Administrations have the responsibility to provide SMEs with all the mechanisms and tools needed to survive in this globalised world. But at the end SMEs will have to make an effort adopting organisational changes and acquiring skills and capacities needed to participate in the future e-Business scenarios.
e-NVISION project builds a set of external web services- Company/Supplier Information Retrieval Service, Supplier/Company Discovery Service, Tender Configurator, Procurement Configurator, Service for the Location of Services, Service Registry, Connector to EU Public Tender Service. These services will be provide by different construction market players - Construction Association, Cluster, Public Administration, Chamber of Commerce, Consultancy Firms.

In the future, a constellation of these semantic web services will be available for SMEs through different intermediaries. The SME will select to which external services it will be subscribed. SMEs can be subscribed to different services, and different organisations could provide similar services competing for SMEs subscription.

\section{REFERENCES}

[1] European Commission (2005a) ICT and Electronic Business in the Construction Industry. European eBusiness Market Watch, Sector Reports No. 08-I and 08-II

[2] European Construction Technology Platform (2005) Challenging and Changing Europe's Built Environment. A vision for a sustainable and competitive construction sector by 2030

[3] Anumba, C. J. \& Ruikar, K. (2002) Electronic commerce in construction-trends and prospects. Automation in Construction, Vol. 11, No. 3, 265-275.

[4] Boddy, S.; Rezgui, Y.; Cooper, G. \& Wetherill, M. (2007) Computer integrated construction: A review and proposals for future direction. Advances in Engineering Software, Vol. 38, No 10, 677-687

[5] e-NVISION project IST-028067 (2007a.) D2.3 "Service-based Reference e-Business Model for SMEs"

[6] e-NVISION project IST-028067 (2007b) D4.2 "Semantic Context Component Architecture"

[7] Hadikusumo, B. H. W.; Petchpong, S. \& Charoenngam, C. (2005) Construction material procurement using Internet-based agent system. Automation in Construction, Vol. 14, No 6, 736-749

[8] European Commission (2005b) Functional Requirements for Conducting Electronic Public Procurement Under the EU Framework 